\title{
Correspondence
}

\section{Suicide prevention}

Sir: Kapur \& House (Psychiatric Bulletin. September 1998, 22, 534-536) try an old trick. adjusting my views on suicide prevention to make them an easier target. They also illustrate their arguments with reference to deliberate selfharm, while my paper (Appleby, 1997) was mainly about mental health services where the issues are similar but not the same.

Kapur \& House run through the, not entirely unfamiliar, story about the distribution of blood pressure in the population to show the value of preventive strategies which are populationbased. But the problem with population strategies is that they do not tell you what to do when it is 4 am and you have two suicidal patients and one bed. For that you need clinical skills. They also imply, in the phrase "with intervention restricted to the high-risk group", that targeting people at high risk would mean discarding the rest - those whose individual risk may be lower but who together contribute most of the suicides. This probably does happen in some self-harm services but in mental health, service input tends to be proportionate to need, including perceived risk of suicide - we may not admit our low-risk patients but we do treat them. However, there is a problem that most of the risk factors on which we base our assessments are common in people with mental illness, and the main purpose of my paper was to consider alternative ways of understanding risk.

Suicide prevention requires a broadly based strategy, one that recognises, as my paper explains in its second paragraph, the influence of social phenomena and at the same time aims to strengthen clinical services. Most commentators on suicide take a similar view and, if I have understood correctly, this is also what Kapur \& House mean by a "combined approach". They even believe they thought of it first.

APPLEBy, L. (1997) Assessment of suicide risk. Psychiatric Bulletin. 21. 193-194.

LOUIS APpleBy, Professor of Psychiatry, Department of Psychiatry. Withington Hospital, West Didsbury, Manchester M20 8LR

Sir: Kapur \& House (Psychiatric Bulletin. September 1998, 22, 534-536) are of course correct in emphasising that suicide prevention overall is dependent upon many factors, over and above those encompassed by face-to-face clinical skills. In my paper (Morgan, 1997), to which they refer. I made it clear that I agree with this and I too emphasised the gross limitations of statistically derived risk factors which aim to predict suicide. particularly when it occurs in the short term. 1 certainly do not propound exclusively a "highrisk strategy" for suicide prevention as they imply.

Nevertheless, I am glad to have the opportunity to clarify what I meant by my assertion that provided we pay sufficient attention to our clinical skills, suicide rates will "look after themselves". My purpose here was to remind clinicians of the paramount importance of clinical skills in both assessing and managing suicide risk. Certainly wider issues such as reducing the availability of method or improving socio-economic conditions are important in their own right. But in our day-to-day work as clinicians we regularly come into face-to-face contact with high-risk individuals, and I believe we have a duty to ensure that the clinical skills such as those I identified in my paper are kept at a high order. Yet where in the literature are these considered systematically, and how do they fit into the present day focus on evidence-based medicine? I fear that in general the evaluation and development of such skills take place far from regularly and at no more than a perfunctory level, although I would be happy to be proved wrong. By all means let us try to alleviate the whole spectrum of possible causes of suicide, but before we distribute our energies widely in such a way should we not ensure first that we have put our own house in order?

MORGan, G. (1997) Management of suicide risk. Psychiatric Bulletin, 21, 214-216.

Gethin Morgan, Emeritus Professor of Mental Health. University of Bristol, Division of Psychiatry, 41 St Michael's Hill, Bristol BS2 8DZ

\section{Stigma campaigns}

Sir: Is a campaign against stigma the losing response of any medical speciality? Is it a good idea to introduce the idea of 'stigma' to those who may agree, but more importantly to those who may not have thought that way until nudged?

Doctors in venereology did not seek to engage us directly about the unpleasantness which can lurk in the moist tufted areas or cavities of our 
neighbours, but adopted a description of their speciality which had an upbeat first and neutral second term (genito- and urinary, respectively). Sometimes this was cleverly reinforced by a move from poor premises outside the walls of hospitals to proper clinics within. Clear messages about the dangers of the conditions and their susceptibility to treatment was an issue, with informed guidance, for central and local health service organisations.

Some of those within psychiatry seem intent on the opposite path.

Is it possible that in psychiatry we have neglected the importance of symbolism, both to our patients and ourselves, in supporting the work we do? Sectorisation, 'community' trusts, the spectre of 'mental health' commissioning authorities, and professors of 'social' and 'community' psychiatry all stigmatise psychiatry as a 'different' medical speciality; we have much to do.

D. M. Bowker, Consultant Psychiatrist, Rochdale Healthcare NHS Trust, Birch Hill Hospital, Rochdale OL12 9QB

\section{Primary care-based mental health promotion drop-in clinic}

Sir: It is difficult to agree with the conclusions of Gilleard \& Lobo (Psychiatric Bulletin, September $1998,22,559-562)$ that "there is a viable role for mental health promotion" in the form of a drop-in clinic based in primary care. Only 55 contacts occurred in 11 months at a twice weekly clinic run by two members of the mental health team. This represents around one patient seen for every 10 hours of professional time, which seems a rather expensive way of distributing information leaflets while informing patients and surgery staff about relevant local non-NHS services. Most general practitioners would consider that a poster in the waiting room would achieve a similar objective and capture a much wider audience at a fraction of the cost.

Paul BlenkIRon, Specialist Registrar in Psychiatry, Department of Liaison Psychiatry. Clinical Sciences Building, St James' University Hospital, Beckett Street, Leeds LS9 7TF

\section{Medical reports for mental health review tribunals}

Sir: Ismail et al (Psychiatric Bulletin, October 1998, 22, 615-618) found at the Maudsley Hospital that three-quarters of Section 3 tribunal reports studied had failed to address completely the statutory criteria for continuing detention, without that failure having affected the outcome of hearings. They advocate replication of their study elsewhere and better training for report writing.

The roles of doctors in mental health review tribunals have been surveyed by Langley (1990) and Woolf (1991). It will always be an essential routine at tribunal hearings to address the statutory criteria orally during the questioning of the doctor who attends to represent the health authority. This is required to establish whether the conclusions of the report need to be amended on the day of the hearing, even for the minority of Section 3 cases in which medical reports are 'complete'.

Of far greater concern for tribunal members, patients' representatives and their independent experts, and for Mental Health Act administrators, is the equally common failure of responsible medical officers to deliver Section 3 reports within the prescribed three weeks (over $70 \%$ at some hospitals).

There may be several good reasons why this happens, including wide misunderstanding of the requirement and its importance. Delays are often justified on the basis that the patient's mental state might change and that it remains to be decided whether the further detention will ultimately be defended. Woolf (1998) has discussed hearings abandoned, often very late and, sometimes inexplicably, without medical reports having been submitted. Early, concise reports, focused upon the key issues, and later supplemented by updates as necessary, make for smoother and better tribunal hearings.

LANGLEY, G. E. (1990) The RMO and mental health review tribunals. Psychiatric Bulletin. 14, 336-337.

Woolf. P. G. (1988) Abortive hearings. MHRT Members News Sheet, 2. 8.

- (1991) The role of the doctor in the mental health review tribunal. Psychiatric Bulletin. 15. 407-409.

P. G. Woolf, Consultant Psychiatrist and Medical Member of MHRT 1966-98, 2a Vanbrugh Hill, London SE3 TUF

\section{Use of placebo}

Sir: There are only a few articles published on the use of placebo, either for diagnostic or treatment purposes; one notable and helpful example being Miller (1988).

I tend to use placebo sometimes for diagnostic purposes but more often as an adjunct in the treatment of anxiety, mild depression and insomnia. Except in one case its use was limited to oral 'medication'. My use of placebo was hotly challenged by visiting commissioners who considered it unlawful. After recent correspondence, the Chief Executive of the Mental Health Act Commission replied following discussion with 